\title{
Graded Assessment Models for Competency-Based Training in Vocational Education and Training
}

\author{
Richard Skiba ${ }^{1, *}$ \\ ${ }^{1}$ LRES Training Management, Melbourne, Australia \\ *Correspondence: LRES Training Management, Melbourne, Australia. E-mail: richard@skiba.com.au
}

Received: May 14, 2020

Accepted: June 17, 2020 Online Published: June 20, 2020

doi:10.5430/wje.v10n3p106

URL: https://doi.org/10.5430/wje.v10n3p106

\begin{abstract}
This exploratory paper considers the practical and theoretical implications of a graded system of assessment in competency-based training within the Australian Vocational Education and Training System. The characteristics of competency-based training are considered and the possible relationships to graded approaches are discussed. The discussion reflects on prominent research in the competency-based assessment domain, including Peddie (1993), Williams and Bateman (2003) and Newton (2018b) to consider the limitations and applications of various models.
\end{abstract}

Keywords: competency based assessment, vocational education and training, assessment practices, graded assessment, vocational education reform

\section{Introduction}

In the Vocational Education and Training (VET) Reform Roadmap Consultation Draft created by the Department of Education, Skills and Employment (2020), a number of priorities for reform in the Australian VET system were identified. The priorities were determined on the basis of the Council of Australian Governments (COAG) agreement on a new shared vision for VET which articulated three priority areas, namely relevance, quality and reliability. One of the recommendations related to improving the quality of education and assessment is the possibility of introducing graded assessment into the VET system. The objective of the reformed assessment practices being to "shift the focus of the system from compliance to excellence, increasing confidence in the system to deliver better outcomes for learners and industry (Department of Education, Skills and Employment, 2020).

Australia's VET system utilises a binary outcome assessment system to record outcomes against competency standards, defined as units of competency, to recognise achievement. The system is outcomes focused and is designed to deliver workplace specific skills and knowledge-based competencies in a range of occupations. Given that competency based training and assessment do not, by their nature, lend themselves well to grades assessment (Peddie, 1993; Williams and Bateman, 2003; McDonald, 2004), there are very few models internationally that can be considered for identification of best practices (Newton, 2018a). Creation and inclusion of a graded approach warrants consideration and exploration of the potential impact on training providers, learners and the industries in which they will work. The study suggests a possible basis for an adjunct graded system to the binary competency-based assessment system based on Anderson and Krathwohl's Taxonomy (Anderson and Krathwohl, 2001).

\section{Method}

This study utilises an exploratory research method, which may also be referred to as interpretative research or grounded theory approach, such that a problem previously studied is investigated to present an improved understanding of the existing problem. The aim of this exploration is to examine the debate to date on the possibility of a graded system of assessment within the competency-based VET system currently in place in Australia, including the effects on the various stakeholders to the system. As much as the study does not aim to produce a conclusive result, conclusions are drawn with respect to possible implementation strategies based on the reviewed research, in particular with respect to Australia's renewed interest in applying grading to Vocational Education and Training. Secondary research data is utilized, by means of literature review, based on existing resources on the subject of grading in competency-based training, as the foundation of the study. The applied method, and in turn the study, lay 
the groundwork that will lead to future studies.

Exploratory and inductive research programs can offer an attractive alternative to the deductive research approach (Bernd, 2017). Exploratory research is a methodological approach that is primarily concerned with discovery and with generating or building theory. Exploratory research is an examination into a subject in an attempt to gain further insight. With Exploratory, a researcher starts with a general idea and uses research as a tool to identify issues that could be the focus of future research. This approach can be used to gain insight into a specific phenomenon and conduct a broad exploration of a topic to gain better knowledge in that field (Yin, 1994; Pratap, 2019), and likewise to gain a better understanding of an issue with a view to generating new ideas and recognising relationships. As stated by Bernd (2017, p139):

"Explorative research instead aims at applying new words, concepts, explanations, theories, and hypotheses to reality with the expectation of offering new ways of seeing and perceiving how this segment of reality works, how it is organized, or, more specifically how and in what way different factors relate to each other causally".

Bernd (2017) explains that by observing and analysing reality from a new and different angle, we can expect to unveil previously hidden facets of reality allowing the researcher to achieve a learning process based on the why and how something happened.

Research in vocational education and training can have a grounding in qualitative or quantitative approaches. Exploratory research approaches can be used in Vocational Education and Training (VET) research to provide new explanations that may been previously overlooked by raising new questions and providing new explanations of a given reality, from a new angle (Bernd, 2017). The approach can make a valuable contribution to development of new knowledge in this educational sector.

\section{Discussion}

\subsection{Competency Based Assessment}

Competency-based assessment is the process of collecting evidence and making judgements about whether a person has achieved competency (Department of Education and Training, 2019). Vocational Education and Training (VET) assessment is centred on a competency-based assessment approach, utilising competency standards which provide benchmarks for the determination of competence in the occupation or task that learners are training in. Effectively, learners are deemed as either 'Competent' or 'Not Yet Competent', following summative assessment, against the competency standard. In this binary reporting, the learner either can, or cannot, demonstrate competence against the competency standard. Meng (2020) defines that competency consists of "knowledge, skills or attributes that are required to perform activities in a given role or fulfill a particular job function effectively". From this perspective, VET assessment emphasises the learner's ability to perform practical tasks and describe or explain how and why tasks are completed in particular ways.

Meng (2020) explains that competency-based training is concerned with outcomes, not the time spent in learning, whereby a learner is said to be competent if they are able to demonstrate that they can perform the outcomes desired. Having completed a training program does not guarantee that a learner will be deemed competent by the Assessor. Determination of competence is based on the collection of evidence, and comparison of the evidence to the specified benchmark. Judgements are made by the Assessor regarding whether the evidence collected meets the required standard. A key component of this assessment approach is that competence means being able to operate in a real-world situation (Meng, 2020), and in a VET context, usually a work environment. Peddie (1993) advises that competency does not refer to "average" or "satisfactory" but rather requires total mastery of learning outcomes.

Other aspects of competency-based assessment approaches, as noted by Meng (2020), are that they are criterion based in that learners are assessed against a standard criteria or benchmark rather than being assessed against each other. These criteria may be defined in competency standards, learning outcomes or other performance outcomes, as specified through the various international VET implementations. Competency-based assessment is also evidence based such that determination of competence is established through evidence demonstrated, produced, gathered, or provided by the learner. The competency-based assessment approach is also founded on supporting underpinning principles of adult learning with the learner actively involved in the assessment process. Evidence of competence is collected through a range of activities and both the assessor and the learner have the scope to negotiate the form of assessment activities. Activities can include, for example, practical demonstration, indirect demonstration, products produced, workplace documents, questions - written and oral, role play, assignments, third party reports, simulation, and portfolios. 


\subsection{Graded System Approaches}

The Productivity Commission (2017), cited in Joyce (2019), identifies that competency-based VET system typically does not differentiate between the proficiency levels of graduates undertaking the same qualification. The Productivity Commission posits that due to the lack of assessment ranks, or proficiency ratings, employers may not have enough information to determine whether they are hiring the best candidate for the job.

There are numerous studies advocating and opposing inclusion of grading within competency-based assessment. Joyce $(2019, \mathrm{p} 48)$ outlines that the Productivity Commission noted the benefits associated with introducing a proficiency-based VET system, stating "that introducing grading would create incentives for students to do well, allow employers to select the best performing candidates for jobs, and boost the reputation of the VET sector as a viable alternative to higher education". Johnson (2007), referring to Smith (2000), suggests that grading can facilitate the motivation for learners to strive for excellence since grading affords the opportunity for this level of performance to be recognised. However, Williams and Bateman (2003) note that whilst more able learners may consider grading to be motivational as it recognises their strengths, lower ability learners might be adversely affected by the practice.

Johnson (2007) informs that It is also important to consider the potential relationship between grading and labelling, noting concerns that learners could internalise the descriptive quality attached to grades to the extent that they infer that their performance and ability is a fixed unchangeable entity. Williams and Bateman (2003) assert that grading adds to the complexity of assessment, reporting that the main drivers for graded assessment come from industry and students, who demonstrate dissatisfaction with binary reporting. Johnson (2007) concurs adding that the opportunity for classification errors in assessment increases resulting from the number of differentiated classifications. The reliability and credibility of the assessment can, in turn, decrease. Further, a study conducted by Richards (2015) found that teachers were evenly divided as to their perceived value of grading and the processes by which grading should be done in a competency-based assessment framework. Richards also found that despite having undergone training in the writing of rubrics, uncertainty and doubt still existed amongst teachers regarding grading within a competency-based training framework.

Peddie (1993) outlines that there are two main notions of merit in a competency-based approach including a merit standard which is much better than the competency standard, and merit awarded on the basis of some quality or qualities other than the competency standard. Peddie $(1993, \mathrm{p} 4)$ further illuminates that "where merit means 'doing better', a merit standard in cases where competency requires complete mastery of the learning outcomes is normally impossible". Schofield and McDonald (2004, p. 19) likewise present that "The use of graded assessment would, for some, undercut the principle of competency-based training". A merit standard, or grading, can however be applied where a unit specifies levels within outcomes. The example provided by Peddie is the inclusion of levels in a typing unit where id the learner can achieve a typing speed of 20 words per minute, they are graded at one level, and at 40 words per minute, at another level.

To maintain a competency-based framework for assessment, the benchmark, in this case the competency standard, is specifically defined and learners are required to fully demonstrate all aspects of the unit of competency. Levels or grades, in this case, imply an outcome of 'Not Yet Competent', where any outcome other than the highest possible grade suggests less than fully competent. It is a well-established premise that a learner is deemed to either competent or not yet competent in a competency-based framework. Were an assessor to provide a percentage grade for a learner of $50 \%$, for example, against a unit of competency, does this imply that the learner is competent $50 \%$ of the time or competent in $50 \%$ of the unit requirements. The binary system is not conducive to grading against competency standards. Further, adding grading criteria adds learning outcomes to a unit which changes the intention of the unit. Peddie (1993) recognises that inclusion of merit ratings or grading focused on a competency standard raises questions relating to the conceptual coherence of the unit standard. Merit or grading, then, could rather be based on "some quality more closely related to the learner, such as their creativity, flair, high level of motivation, or the ease with which they are able to transfer learning from one domain to another" (Peddie, 1993, p4).

Grading could also potentially be used by employers for candidate selection rather than attainment of competency. Peddie (1993) concurs with the notion that the main purpose of a merit standard is to allow selection of the 'best', which is presumably a small proportion of the learners. As such, the grading criteria could have adverse effects on learners unable to attain the higher grades as outlined by Williams and Bateman (2003). Johnson (2007) recognises that use of grading in competency-based assessments could demotivate and discourage some learners.

Johnson (2007) advises that a method of overcoming some of the noted problems related to grading in competency-based assessments is to grade outcomes once competence has been established. Schofield and McDonald (2004) advocate the use of grading in competency-based training as long as it remains as supplementary 
reporting. Johnson does however notes that one of the problems for competency-based assessment utilising grading together with a binary system, is that qualification users might mistakenly assume that graded performance reporting is based on norm-referenced principles, as also noted by Williams and Bateman (2003) and Peddie (1997). An opportunity exists for assessors to become confused between the two approaches to assessment. Assessors may have difficulty in discerning between the two approaches and may end up tying them together. Johnson (2007) surmises that in practice, the potential benefits of grading would need to be balanced against its potential disadvantages.

Newton (2018a) informs that it is now UK Government policy to promote grading within Vocational and Technical Qualifications (VTQs) and in new Apprenticeships. This policy has been implemented on the basis that a graded approach motivates learners to achieve a high level of proficiency, and to provides qualification users with high quality information on candidates' proficiency levels. Regarding best practice approaches to grading in competency-based assessment, Newton (2018a) suggests that there is no authoritative literature on grading in VET contexts, however, notes that grading is theorised and practised differently to binary competency-based assessments, and depends on the purpose(s), context(s), and population(s) targeted by the assessment procedure. The dominant model in England is based on a process by which grade boundaries are located along component-level mark scales, from which qualification-level grade boundaries are derived (Newton, 2018a).

\subsection{Verification of Competency}

Joyce (2019) outlines that some industries overcome assessment concerns through the independent validation of a person's competencies at the end of the course, which can be conducted as a capstone assessment or through independent licensing requirements. Independent licencing requirements, for example can include builder registration, high risk work licencing such as for specific plant and equipment, or heavy vehicle licencing. Joyce, referring to the Victorian Skills Commissioner (2017), notes that despite a number of industries using independent validation of assessment outcomes, the majority of VET is not currently independently assessed. Employers may also access verification of competency processes.

Verification of competency processes are particularly beneficial where new technology or equipment is introduced that may not have been included in previous training, new work practices or procedures are introduced or where new legislative or standards requirements are introduced (WorkCover Queensland, 2018). These verifications are often used in some industries for pre-employment checks, contractual arrangements or to meet specific site requirements. Verification of competency can be undertaken by the employer of through a training provider through a formal nationally recognised program or through an unaccredited program. Verifications undertaken in this way are generally not part of the Nationally Recognised Training system and not following a nationally consistent approach. In this context, a Verification of Competency is an independent assessment used to verify competence and current compliance assisting employers to meet Work Health and Safety requirements. The verification also ensures staff are still competent to operate equipment or perform a task.

Due to changes in the health and safety legislation in 2012 throughout much of Australia, employers/'persons conducting a business or undertaking' (PCBUs) have an increased obligation to ensure people they employ or hire are competent to undertake the tasks they have been engaged to perform. Given this obligation is on the employer/PCBU, holding a licence or certification does not cover this obligation, and employers/PCBUs are required to show evidence of how they have determined competency. As such, there is an increased focus on Verification of Competence and as a result, a secondary system of assessment has emerged that sits alongside the Nationally Recognised Vocational Education and Training system in Australia. There are a number of training providers that deliver nationally recognised or accredited training as well as accredited verification of competency programs.

Units of competency define competency standards which can be used to benchmark assessment activities. No such benchmark exists for Verification of Competency programs. Within the nationally recognised VET system, units of competency provide for a level of consistency, transferability and mobility, where the responsibility is placed onto the employer to determine competence, in order to meet their obligations under health and safety legislation. On this basis, two levels of competency assessment exist, one conducted by a Registered Training Organisation (RTO), under a regulated system, and one conducted by employers.

Trainers and Assessors undertaking training and assessment activities within an RTO are required to meet skills, knowledge and qualification criteria. These include having attained vocational competencies at least to the level being delivered and assessed, possessing current industry skills directly relevant to the training and assessment being provided and current knowledge and skills in vocational training and learning that informs their training and assessment (Australian Skills Quality Authority, 2020). Trainers and Assessors are also required to hold the qualification TAE40116 Certificate IV in Training and Assessment or its successor, or TAE40110 Certificate IV in 
Training and Assessment with TAELLN411 (or its successor) or TAELLN401A, and TAEASS502 (or its successor) or TAEASS502A or TAEASS502B or a diploma or higher level qualification in adult education. As such, there are very specific requirements for Assessors, as determined by the Standards for RTOs 2015, conducting assessments for RTOs, where there are no such defined standards for Verification of Competence activities.

Obtaining a qualification through the vocational education and training system then, does not guarantee that the graduate is job ready as the employer is required to make the determination. This situation exists irrespective of the assessment models applied within Vocational Education and Training, including where there are licenced outcomes. As an example, an individual completing the unit of competency "TLILIC0003 - Licence to operate a forklift truck", can not operate a forklift in a workplace until they are licenced to do so. They must meet the state or territory requirements for issuance of a high-risk licence, undertaken utilising mandatory national assessment instruments, Forklift truck operation licence LF. Once the licence is attained, the individual may then have to demonstrate competence for a third time to the employer, as a verification of competency, prior to commencing any work. In each case, there are different assessment requirements, approaches and standards. Given the multiple layers of assessment that exist in this scenario, there are many opportunities for confusion amongst the stakeholders, including trainers, assessors, students, employers and regulators.

Schofield and McDonald (2004, p. 20) outline that "regulators will continue to develop their own criteria over and above VET requirements, reflecting their mission to protect the community". On this basis, any additional inclusions of assessment requirements in the VET sector, such as grading, will not necessarily filter through to the assessment practices applied for verification of competence or in licence testing.

Vocational education and training plays a significant role in the preparation of learners for job readiness. A generic and fundamental aspect of workplace related training is the development of health and safety in work practices. Each and every job role has its own inherent safety aspects and learners must demonstrate mastery of learning outcomes, as advocated by Peddie (1993). Given the importance of health and safety, holistic and complete competence is essential. This mastery is related to demonstration of competence with regard to the underpinning competency standard. The unit of competency forms this standard and the learner is required to provide evidence in all aspects of the unit.

\subsection{Implementation of Graded Approaches}

Newton (2018b) suggests that transforming a binary competency-based assessment system into a grading approach involves specifying higher-level criteria for either for each and every, or for a restricted set of, assessment criteria. These criteria essentially need to be added to, or outside of, competency statements.

As an example of separate and concurrent assessment criteria being applied alongside the binary determination of competence, Newton (2018b) describes an approach to use of merit criteria as applied in the UK Business and Technology Education Council (BTEC) Level 5 Electrical Higher National Diploma that awards Pass, Merit and Distinction grades across units. These grades are used to judge the full complement of the work produced from the unit and are distinct from the Assessment Criteria of the unit. Merits are awarded based on additional criteria specified as: identify and apply strategies to find appropriate solutions; select/design and apply appropriate methods/techniques; and, present and communicate appropriate findings. A Distinction grade is awarded on the basis of: use critical reflection to evaluate own work and justify valid conclusions; take responsibility for managing and organising activities; and, demonstrate convergent/lateral/creative thinking. Newton (2018b) posits that these are used as 'indicative characteristics'.

There are a number of approaches that can be applied regarding the measurement system to be applied within a graded approach. Newton (2018b) describes some of these approaches, including Description-related, Criterion-related, Performance quality criterion-related and Performance complexity criterion-related grading. In description-related grading approaches a grading rubric is utilised which specifies the characteristics for each grade. These rubrics can be specified to focus on the characteristics of interest to industry or employers beyond competency attainment. Criterion-related grading approaches include development of additional criteria for grading that are directly mapped to, or onto, assessment criteria derived from the competency standard. In this approach, greater proficiency than that of the competency standard is specified as the additional criteria go beyond the assessment criteria. In the UK, Newton (2018b) notes that there are criterion-related grading approaches that differentiate primarily in terms of performance quality and those that differentiate primarily in terms of performance complexity, from the underpinning competency standard.

Performance quality criterion-related grading requires repeating each assessment criteria, or performance criteria, 
with an indication of level. Using an example as provided by Newton (2018b), for a Pass grade specifying the criteria as "explain the marketing strategy...", for a Merit grade as "Explain with clarity and detail...." and for a Distinction grade "Comprehensively explain...". A unit level aggregation process is then required to determine the unit grade. Within a performance complexity criterion-related grading, Newton (2018b) explains "grades for units from this qualification are not differentiated primarily on the basis of performance quality, but on the basis of performance complexity, expressed in terms of a progression in command verb challenge". As examples, criteria may be specified as "explain the importance of the..." for a Pass grading, "discuss the key points relating to..." and as "analyse the properties of a range of..." for a Merit grade. Performance complexity criterion-related grading introduces levelling to competency standards where a unit's assessment criteria are defined to align with various levels allowing for grading to take place. Irrespective of the approach taken, in order to maintain consistency in assessment judgements, a common grading scheme leading to objective and consistent reporting would need to be developed. The graded assessment centres on learner traits and describes a particular learner's proficiency rather than documenting competence.

As a basis for an adjunct grading system, an approach based on the Anderson and Krathwohl's Taxonomy, being a revised version of Bloom's Taxonomy (Anderson and Krathwohl, 2001), referring to cognitive process and knowledge dimensions could be considered. The cognitive dimensions include: Remember - recall; Understand meaning making; Apply - using procedures; Analyse - breaking down into parts, finding relationships and structure; Evaluate - make judgments, critique; and Create - generate products (Learning Futures, 2020). The knowledge dimensions include: Factual knowledge - basic elements of knowledge; Conceptual knowledge - the interrelationships between the basic elements; Procedural knowledge - skills, methods, techniques; and, Metacognitive knowledge - awareness and knowledge of self. These dimensions are organised hierarchically and can be used as a basis for grading levels where transformed to learning objectives. The cognitive process dimension represents a continuum of increasing cognitive complexity, from remember to create, and the knowledge dimension represents a range from concrete or factual to abstract or metacognitive (Iowa State University, 2020).

Wilson (2016) provides definitions of each of the dimensions, for example, "Remembering: Recognizing or recalling knowledge from memory. Remembering is when memory is used to produce or retrieve definitions, facts, or lists, or to recite previously learned information" and "Understanding: Constructing meaning from different types of functions be they written or graphic messages or activities like interpreting, exemplifying, classifying, summarizing, inferring, comparing, or explaining". These can be rephrased into observable learning behaviours such that a learner can be identified at a level and assigned a corresponding grade. These specifications could be applied generically to any learning unit. This approach would grade a learner's knowledge and cognitive characteristics rather than competence, which is determined using established binary methods.

\section{Conclusion}

Competency based assessment calls for a binary result, namely 'Competent' and 'Not Yet Competent' rather than a graded outcome. Nevertheless, grading can be used alongside the determination of competence and should be applied once an individual has been deemed to be competent. The grading system applied is dependent on its purpose, particularly where the implementation is driven by social, political, industrial, or regulatory forces. The grading scheme, in order to minimise confusion and misinterpretation, should not include elaborate and complex rubrics that are difficult for learners, assessors and industry to interpret. Introduction of a graded system to record proficiency or personal traits on top of a binary system utilised to record competence, should not increase the level of complexity in an already complex system.

\section{References}

Anderson, L. W. (Ed.), Krathwohl, D. R. (Ed.), Airasian, P. W., Cruikshank, K. A., Mayer, R. E., Pintrich, P. R., Raths, J., \& Wittrock, M. C. (2001). A taxonomy forlearning, teaching, and assessing: A revision of Bloom's Taxonomy of Educational Objectives (Complete edition). New York: Longman.

Australian Skills Quality Authority. (2020). Clauses 1.13 to 1.16-Employ skilled trainers and assessors. Retrieved from https://www.asqa.gov.au/standards/training-assessment/clauses-1.13-to-1.16

Bernd, R. (2017). Theory and Methodology of Exploratory Social Science Research. International Journal of Science and Research Methodology, 5(4), 129-150.

Department of Education and Training. (2019). Fact Sheet: Competency-Based Training. Retrieved from 
https://www.myskills.gov.au/media/1776/back-to-basics-competency-based-training.pdf

Department of Education, Skills and Employment. (2020). Vocational Education and Training (VET) Reform

Roadmap Consultation Draft. $\quad$ Retrieved from
https://docs.employment.gov.au/documents/vocational-education-and-training-vet-reform-roadmap-consultation -draft

Iowa State University. (2020). Revised Bloom's Taxonomy. Retrieved from https://www.celt.iastate.edu/teaching/effective-teaching-practices/revised-blooms-taxonomy/

Johnson, M. (2007). Is passing just enough? Some issues to consider in grading competence-based assessments. Research Matters, 1(3), 27-30.

Joyce, S. (2019). Strengthening Skills: Expert Review of Australia's Vocational Education and Training System. Commonwealth of Australia, Department of the Prime Minister and Cabinet.

Learning Futures. (2020). Bloom's taxonomy of educational objectives. Retrieved from https://app.griffith.edu.au/exlnt/entry/8408/view

Meng, S. T. (2020). Competency-Based Learning and Assessment. Retrieved from https://www.aptsg.com/index.php/articles-2/20-for-all/31-competency-based-learning-and-assessment

Newton, P. E. (2018a). Research and Analysis: Overview -Grading Vocational \& Technical Assessments. Ofqual.

Newton, P. E. (2018b). Research and Analysis: Grading Vocational \&Technical Qualifications - Recent policies and current practices. Ofqual.

Peddie, R. (1993). 'Levels, grades and merit in competency-based assessment', in testing times: a national conference on assessment for competency-based training: conference papers, part two. NCVER, Adelaide.

Pratap, A. (2019). Research design and its types: Exploratory, descriptive and causal. Retrieved from https://notesmatic.com/2018/07/research-design-and-its-types-exploratory-descriptive-and-causal/

Richards, J. (2014). An old chestnut revisited: Teachers' opinions and attitudes toward grading within a competency based training framework. International Journal of Training Research, 12(3), 182-191. https://doi.org/10.1080/14480220.2014.11082040

Schofield, K., \& McDonald, R. (2004). Moving on: Report of the high level review of training packages. Australian National Training Authority: Melbourne.

Smith, L. R. (2000). Issues impacting on the quality of assessment in vocational education and training in Queensland. Brisbane: Department of Employment, Training and Industrial Relations.

Victorian Skills Commissioner. (2017). Rebalance and Relaunch: Supporting Victoria's economy by enhancing apprenticeship and traineeship pathways as a mechanism for skilling the future workforce. Victoria, Victoria State Government.

Williams, M., \& Bateman, A. (2003). Graded assessment in vocational education and training. Kensington Park, South Australia: NCVER.

Wilson, L. O. (2016). Anderson and Krathwohl Bloom's Taxonomy Revised: Understanding the New Version of Bloom's Taxonomy. Retrieved from https://quincycollege.edu/content/uploads/Anderson-and-Krathwohl_Revised-Blooms-Taxonomy.pdf

WorkCover Queensland. (2018). Verification of competency. Retrieved from https://www.worksafe.qld.gov.au/forms-and-resources/newsletter/esafe-newsletters/esafe-editions/esafe-electric al/2018-bulletins/verification-of-competency

Yin, R. K. (1994). Case Study Research Design and Methods: Applied Social Research and Methods Series (2nd ed.). Thousand Oaks, CA: Sage Publications Inc. 